\title{
Estado nutricional do coqueiro cultivado em solos submetidos a diferentes níveis de compactação e umidade
}

\author{
Romano R. Valicheski ${ }^{1}$, Cláudio R. Marciano ${ }^{2}$, Anderson L. Peçanha ${ }^{3}$, \\ Rejane S. Bemardes ${ }^{4} \&$ Pedro H. Monnerat ${ }^{5}$
}

\begin{abstract}
RESU M 0
Com o objetivo de avaliar o efeito da compactação e da umidade do solo na absorção de nutrientes pelo coqueiro anão-verde, implantou-se um experimento em casa de vegetação em Campos dos G oytacazes, RJ. 0 delineamento experimental utilizado foi em blocos casualizados com tratamentos distribuídos em esquema fatorial $(2 \times 4 \times 4)$, com três repetições, sendo duas classes de solo (Argissolo Amarelo Distrocoeso latossólico e Cambissolo H áplico Tb Distrófico típico gleico), quatro níveis de compactação em subsuperfície e quatro condições hídricas. Os solos atuaram de forma diferenciada no suprimento de nutrientes, sendo determinado o teor foliar de $\mathrm{Mg}$ e $\mathrm{Cu}$ mais elevado nas plantas cultivadas no Cambissolo e os de $\mathrm{K}$ e Ca nas cultivadas no Argissolo. 0 incremento da umidade do solo alterou a disponibilidade de nitrogênio no Argissolo fazendo com que as plantas cultivadas nos maiores níveis de umidade apresentassem teor foliar mais elevado de $\mathrm{N}$. Também no Argissolo a compactação afetou a absorção de manganês e cloro observando-se, nas plantas cultivadas nos níveis mais elevados de compactação, teor foliar maior de $\mathrm{Mn}$ e menor de $\mathrm{Cl}$.
\end{abstract}

Palavras-chave: densidade do solo, umidade do solo, absorção de nutrientes, Cocos nucifera L.

\section{Nutritional status of coconut grown in soils submitted to different compaction and moisture levels}

\begin{abstract}
A B ST RAC T
In order to evaluate the effect of compaction and moisture in absorption of by greennutrients dwarf coconut plants, an experiment was carried out under greenhouse, in Campos dos Goytacazes, RJ. The experimental design was in randomized block in factorial scheme $(2 \times 4 \times 4)$, with three repetitions. The treatments were 2 soil classes (Typic Kandiudult and U mbric Dystrochrept), 4 levels of soil compaction and 4 water levels. The soils were differentiated in the nutrient supply, with higher levels of $\mathrm{Mg}$ and $\mathrm{Cu}$ in plants cultivated in U mbric Dystrochrept and $\mathrm{K}$ and $\mathrm{Ca}$ in Typic Kandiudult soil. The elevation of soil moisture altered the availability of nitrogen, so plants cultivated in Typic Kandiudult soil presented higher levels of $\mathrm{N}$ in leaves under in the highest soil moisture level. In Typic Kandiudult, the compaction affected the $\mathrm{Mn}$ and $\mathrm{Cl}$ absorption, with higher levels of $\mathrm{Mn}$ and smaller of $\mathrm{Cl}$ occurring in the plants cultivated with highest levels of compaction.
\end{abstract}

Key words: soil density, soil moisture, nutrient absorption, Cocos nucifera L.

\footnotetext{
${ }^{1}$ Instituto Federal Catarinense-Campus Rio do Sul, Estrada do Redentor, 5665, Bairro Canta Galo, CEP 89160-000, Rio do Sul, SC. Fone: (47) $3531-3700$. E-mail: romano@ifc-riodosul.edu.br

${ }^{2}$ Laboratório de Solos/U EN F, Av. Alberto Lamego 2000, Bairro Parque Califórnia, CEP 28013-602, Campos dos G oytacazes, RJ. Fone: (22) $2733-4783$. E-mail: marciano@uenf.br

${ }^{3}$ D outorando, Laboratório de M elhoramento Genético Vegetal/U EN F. Fone: (22) 2733-4783. E-mail: apecanha@uenf.br

4 D outoranda, Laboratório de Solos/UENF. Fone: (22) 9261-7053. E-mail: rejane@uenf.br

${ }^{5}$ Laboratório de Fitotecnia/U EN F. Fone: (22) 2725-1427. E-mail: monnerat@uenf.br
} 


\section{INTRODUÇÃO}

Embora cultivado predominantemente nos solos arenosos do litoral da Região Nordeste do Brasil, o coqueiro vem sendo interiorizado na própria Região e levado às regiões Norte, Sudeste e Centro-Oeste. Este deslocamento para áreas não convencionalmente cultivadas trouxe, como consequência, uma série de problemas tecnológicos, a maioria ainda em fase de estudo (Marinho et al., 2006). Alguns desses problemas são decorrentes da baixa disponibilidade hídrica e da compactação do solo, os quais afetam, entre outros aspectos, a absorção de nutrientes pelas plantas.

Quanto ao estado nutricional do coqueiro anão-verde, Santos (2002) determinou, na folha número 2 de plantas com 3 anos de idade e bom desenvolvimento, teores médios de 21 , 11, 7, 3,8, 2, 1,7 e 2,0 $\mathrm{g} \mathrm{kg}^{-1}$ para, respectivamente, $\mathrm{N}, \mathrm{K}, \mathrm{Cl}, \mathrm{Ca}$, $\mathrm{P}, \mathrm{Mg}$ e S. Já Alves (2003), encontrou, em plantas com sete anos de idade e produção superior a 268 frutos planta ${ }^{-1} \mathrm{ano}^{-1}$, teores em $\mathrm{g} \mathrm{kg}^{-1}$, de 18,2 a 19,7 para N; 1,10 a 1,40 para P; 7,80 a 10,4 para K; 4,26 a 4,51 para Ca; 2,79 a 3,77 para Mg; 1,29 a 1,75 para $\mathrm{S}$ e 8,06 a 10,8 para $\mathrm{Cl}$, e teores em $\mathrm{mg} \mathrm{kg}^{-1}$, de 17,9 a 19,5 para B, 2,74 a 5,98 para Cu, 99 a 182 para Fe, 16,0 a 24,0 para $\mathrm{Mn}$ e 7,26 a 8,56 para $\mathrm{Zn}$, considerando-os adequados para esta cultura.

Segundo Teixeira et al. (2005a; 2005b), a falta de condições adequadas, no que se refere ao estado nutricional do coqueiro, poderá interferir no crescimento vegetativo e na produção. Sobral (1998) descobriu, monitorando os solos nordestinos plantados com coco, que grande parte possuía quantidades inadequadas de $\mathrm{N}$ e $\mathrm{K}$ para a cultura.

Devido à sua gênese, nos solos dos Tabuleiros Costeiros ocorrem camadas coesas/adensadas em subsuperfície (Cintra et al., 2004). Tanto nos solos dos Tabuleiros Costeiros quanto em outros com textura média ou argilosa, é comum a presença de camadas compactadas em superfície e subsuperfície, resultantes do tráfego intenso de máquinas na limpeza do pomar, tratamentos fitossanitários e colheita. A compactação do solo altera de forma expressiva o crescimento radicular (Foloni et al., 2003; Beutler \& Centurion, 2004; Cardoso et al., 2006), a disponibilidade hídrica (Silva et al., 2006; Lipiec \& Hatano, 2003), a aeração (Hanza \& Anderson, 2005), o fluxo difusivo e a absorção de nutrientes pelas plantas (Costa et al., 2009; Ahmed et al., 2009; Rodrigues et al., 2009), cujos efeitos são variáveis conforme o solo, a cultura e o sistema de manejo adotado (Ralisch et al., 2008; Oliveira et al., 2010).

Atualmente, devido ao processo de compactação ao qual estão sendo expostos, diversos tipos de solo vêm perdendo a qualidade física. Mundialmente e em razão de ter atingido aproximadamente 68 milhões de hectares, este processo se destaca como um dos principais fatores que têm limitado a obtenção de maiores índices de produtividades (Alakukku et al., 2003). Corrêa et al. (1998) constataram, avaliando cultivares de cana-de-açúcar em solos sob diferentes níveis de compactação, alterações no teor de nutrientes na parte aérea das plantas, reduzindo as concentrações de $\mathrm{Zn}, \mathrm{B}$ e Fe e aumentando as de $\mathrm{S}, \mathrm{K}$ e $\mathrm{N}$, independente da cultivar de cana e do solo. Para o fósforo, no entanto, esses autores verificaram aumento da concentração na parte aérea da planta no cultivo em Latossolo Vermelho textura média e redução em Latossolo Vermelho textura argilosa, independente da variedade de canade-açúcar testada. Já Ahmad et al. (2009) observaram, cultivando trigo em solo submetido a diferentes densidades que, com o incremento da compactação do solo, há uma redução na quantidade de $\mathrm{N}, \mathrm{P}$ e $\mathrm{K}$ absorvidos pelas plantas.

A compactação também aumenta a interação dos íons fosfato e potássio com a superfície dos colóides do solo, ao longo de sua trajetória de difusão, fazendo com que esses elementos tenham que se difundir cada vez mais próximo de superfícies providas de cargas que os adsorvem (Santos et al., 2008). Ao estudar a difusão de fósforo em dois Latossolos (textura média e argilosa) submetidos a três níveis de umidade, Villani et al. (1993) constataram redução na difusão de P com o decréscimo da umidade, em ambos os solos. Apesar disto, a difusão de $\mathrm{P}$ no solo de textura média foi duas a três vezes maior do que a observada no solo com textura argilosa, ambos sob umidade correspondente à tensão de $10 \mathrm{kPa}$, concluindo que o efeito depressivo da menor disponibilidade de água sobre a difusão deste nutriente será bem mais drástico nos solos argilosos do que nos solos arenosos. Barzegar et al. (2006), ao estudarem o efeito da compactação do solo na absorção de $\mathrm{P}$ e $\mathrm{Zn}$ por plantas de trevo egípcio, contataram redução da absorção desses nutrientes com o incremento da compactação, sugerindo o aumento moderado do suprimento de Zn e P, para amenizar os efeitos da compactação. Resultado similar foi constatado por Santos et al. (2005), para a aplicação de P no cultivo de milho.

Segundo Queiroz-Voltan et al. (2000), em solos compactados as raízes das plantas não utilizam adequadamente os nutrientes disponíveis, uma vez que o desenvolvimento de novas raízes, responsáveis pela absorção de água e nutrientes, fica prejudicado. Além disso, os autores mencionam que a quantidade de oxigênio na rizosfera pode ser limitante nos processos metabólicos. Segundo Hakansson et al. (1998), em solos compactados o menor desenvolvimento do sistema radicular resulta em menor volume de solo explorado pelas raízes e, consequentemente, em menor absorção de água e nutrientes.

Objetivou-se, com este trabalho, avaliar o estado nutricional do coqueiro anão cultivado em duas classes de solo submetidas a diferentes níveis de compactação e umidade.

\section{Material e MÉTOdos}

O ensaio foi realizado em condição de casa de vegetação (8 x $50 \mathrm{~m}$ ) na Estação Experimental da Empresa de Pesquisa Agropecuária do Rio de Janeiro (PESAGRO-RIO), em Campos

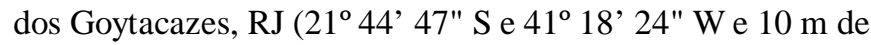
altitude). O clima, segundo a classificação de Köppen, é do tipo Aw, isto é, tropical úmido, com verão chuvoso e inverno seco. O delineamento adotado foi de blocos casualizados com três repetições (uma planta por parcela), sendo os tratamentos distribuídos em esquema fatorial $2 \times 4 \times 4$, sendo os fatores duas classes de solo, quatro níveis de compactação do solo e quatro condições de umidade, totalizando 96 parcelas, em que cada uma correspondeu a um vaso plástico com 
Tabela 1. Atributos químicos do Argissolo Amarelo Distrocoeso latossólico (PAdx) e do Cambissolo Háplico Tb Distrófico típico gleico (CXbd) antes do plantio do coqueiro anão-verde

\begin{tabular}{|c|c|c|c|c|c|c|c|c|c|c|c|c|}
\hline \multirow{2}{*}{ Solo } & \multirow{2}{*}{$\begin{array}{c}\mathrm{pH} \\
\text { água }\end{array}$} & \multirow{2}{*}{$\begin{array}{c}\mathbf{P} \\
\left(\mathrm{mg} \mathrm{kg}^{-1}\right)\end{array}$} & \multirow{2}{*}{$\begin{array}{c}\mathrm{C} \\
\left(\mathrm{g} \mathrm{kg}^{-1}\right)\end{array}$} & $\mathrm{Al}^{+3}$ & $\mathrm{H}^{+}+\mathrm{Al}^{+3}$ & $\mathrm{Ca}^{+2}$ & $\mathrm{Mg}^{+2}$ & $\mathrm{~K}^{+}$ & $\mathrm{Na}^{+}$ & SB & CTC & V \\
\hline & & & & \multicolumn{8}{|c|}{$\left(\mathrm{mmol}_{\mathrm{c}} \mathrm{kg}^{-1}\right)$} & $\%$ \\
\hline PAdx & 4,93 & 2,30 & 6,44 & 0,33 & $\begin{array}{l}19,2 \\
38,8\end{array}$ & 13,5 & 5,8 & 0,6 & 0,4 & 20,3 & 39,4 & 51 \\
\hline
\end{tabular}

aproximadamente $0,4 \mathrm{~m}$ de altura e $0,6 \mathrm{~m}$ de diâmetro, preenchido com $100 \mathrm{dm}^{3}$ de solo.

Os solos utilizados foram um Argissolo Amarelo Distrocoeso latossólico (PAdx) e um Cambissolo Háplico Tb Distrófico típico gleico (CXbd), classificados de acordo com EMBRAPA (2006), coletados homogeneamente da superfície até a profundidade de 1,2 m (PAdx) e de 0,3 m (CXbd). Após a coleta o solo foi passado em peneira com malha de $6 \mathrm{~mm}$ e coletadas três amostras compostas de cada solo para análises química e física, cujos atributos constam nas Tabelas 1 e 2 (EMBRAPA, 1997). Determinou-se a granulometria a partir da dispersão de $20 \mathrm{~g}$ de solo em frasco de $800 \mathrm{~mL}$ com $20 \mathrm{~mL}$ de $\mathrm{NaOH}+250 \mathrm{~mL}$ de água e agitação durante $16 \mathrm{~h}$ a 120 ciclos por min., obtendose a areia com o uso de peneira com malha de $53 \mathrm{~mm}$, a argila pelo método da pipeta e o silte por diferença. A densidade das partículas foi determinada pelo método do balão volumétrico.

Tabela 2. Composição granulométrica e densidade de partículas do Argissolo Amarelo D istrocoeso latossólico (PAdx) e do Cambissolo Háplico Tb Distrófico típico gleico (CXbd)

\begin{tabular}{ccccc}
\hline Solo & Areia & $\begin{array}{c}\text { Silte } \\
\left(\mathbf{g ~ k g}^{-1}\right)\end{array}$ & $\begin{array}{c}\text { Argila } \\
\text { PAdx }\end{array} 469 \begin{array}{ccc}\text { Densidade de partículas } \\
\left(\mathbf{M g ~ m}^{-3}\right)\end{array}$ \\
CXbd & 482 & 120 & 474 & 2,68 \\
\hline
\end{tabular}

Além da avaliação inicial do solo as amostras compostas foram utilizadas para determinar a densidade mínima ( $\rho$ mín), obtida pelo acondicionamento do solo em anel volumétrico sem aplicação de carga e para a realização do teste de Proctor normal (Stancati et al., 1981), cujo resultado para cada soloé uma curva relacionando a densidade obtida no ensaio e a umidade gravimétrica (Figura 1). Igualando-se a zero a derivada primeira das equações ajustadas pode-se estimar os valores de umidade (U) em que ocorre a máxima compactação. Por outro lado, a substituição dessas umidades nas equações primitivas apresentadas na Figura 1 resulta nos valores de densidade máxima correspondente ( $\rho$ máx). A partir da diferença entre a densidade máxima e a densidade mínima foi possível determinar a amplitude de variação da densidade do solo ( $\Delta$ ds = $\rho$ máx - $\rho$ mín $)$.

$\mathrm{O}$ acondicionamento dos solos nos vasos foi feito de forma a se obter uma altura total de $0,4 \mathrm{~m}$, sendo a camada superficial de $0,1 \mathrm{~m}$ não compactada e a camada de $0,3 \mathrm{~m}$ imediatamente

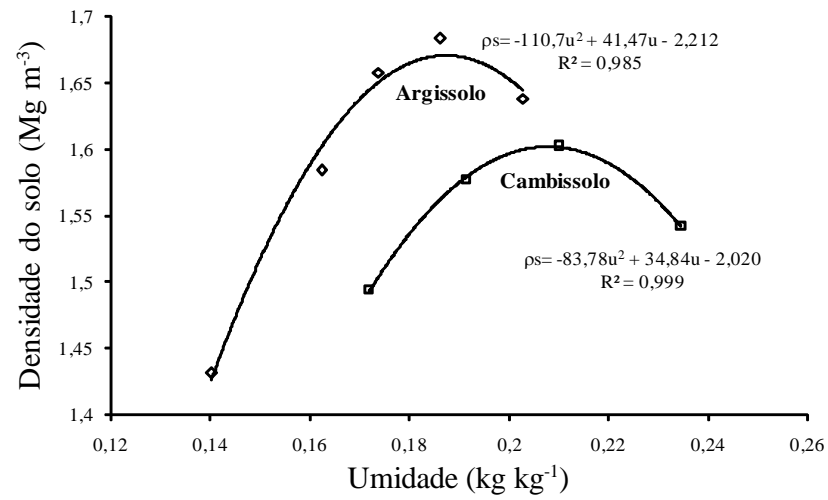

Figura 1. Relação entre umidade e densidade obtida no teste de Proctor normal para o Argissolo Amarelo e o Cambissolo Háplico

abaixo, compactada em um dos quatro níveis estudados ( $\rho$ mín, pmín $+30 \%$ da $\Delta$ ds, $\rho$ mín $+60 \%$ da $\Delta$ ds e $\rho$ mín $+90 \%$ da $\Delta$ ds ). As densidades de solo obtidas em cada nível de compactação para cada solo, bem como a amplitude de variação ( $\Delta \mathrm{ds})$, são apresentadas na Tabela 3. A quantidade de solo a ser acondicionada em cada vaso para que se atingisse a densidade estabelecida foi calculada por pesagem, sendo a massa de solo úmido utilizada em cada nível de compactação obtida a partir da massa necessária de solo secado em estufa e da umidade gravimétrica do solo (determinada em amostra de solo coletada no dia anterior ao acondicionamento).

Para a implementação dos níveis de compactação utilizouse uma prensa hidráulica. Para maior eficiência do processo de compactação a umidade foi elevada ao valor ótimo obtido no teste de Proctor normal. Além disso, para se obter uma compactação mais homogênea, a massa de solo utilizada em cada parcela experimental foi subdividida em cinco partes iguais, compactadas sequencialmente em camadas de 0,06 $\mathrm{m}$ de espessura, até que se atingisse $0,3 \mathrm{~m}$. Para a camada superficial de 0,1 m não foi conveniente a aplicação de pressão.

A necessidade de calagem foi determinada pelo método de saturação por bases, sendo a quantidade de calcário (com PRNT de 85\%) aplicada por vaso, nos níveis de compactação 1, 2, 3 e 4, respectivamente, de 34,5, 41,5, 48,5 e 55,5 g para o PAdx, e de 93,3, 110,1, 126,9 e 143,8 g para o CXbd. NoArgissolo, além da calagem tornou-se necessário fazer a correção da deficiência de $\mathrm{P}$ aplicando-se, em cada vaso e nesses níveis de

Tabela 3. U midade (U ) para compactação máxima, densidade do solo mínima ( densidade do solo ( $\triangle$ ds) e densidades utilizadas nos quatro níveis de compactação ( $C p 1, C p 2, C p 3$ e Cp4), para o Argissolo Amarelo Distrocoeso latossólico (PAdx) e do Cambissolo Háplico Tb Distrófico típico gleico (CXbd)

\begin{tabular}{|c|c|c|c|c|c|c|c|c|}
\hline \multirow{2}{*}{ Solo } & \multirow{2}{*}{$\begin{array}{c}U \\
\left(\mathrm{~kg} \mathrm{~m}^{-3}\right)\end{array}$} & pmín & $\rho \max$ & $\Delta \mathrm{ds}$ & Cp1 & Cp2 & Cp3 & Cp4 \\
\hline & & \multicolumn{7}{|c|}{$\left(\mathrm{Mg} \mathrm{m}^{-3}\right)$} \\
\hline Argissolo & 0,187 & 1,00 & 1,67 & 0,67 & 1,00 & 1,20 & 1,40 & 1,60 \\
\hline Cambissolo & 0,208 & 1,00 & 1,60 & 0,60 & 1,00 & 1,18 & 1,36 & 1,54 \\
\hline
\end{tabular}


compactação, 280,0, 336,4, 392,74 e 449,5 g de super fosfato simples. A calagem, tal como a adubação fosfatada, foi realizada durante o acondicionamento do solo nos vasos.

Em 15/03/2006 uma muda de coqueiro anão-verde foi transplantada no centro de cada vaso, tendo-se cuidado para não enterrar o coleto. As mudas estavam com 12 semanas de idade, 3 a 4 folhas primárias e coleto com 3 a $5 \mathrm{~cm}$ de diâmetro. $\mathrm{Na}$ ocasião do transplante foi efetuada a poda das raízes e mantido o fruto que deu origem à planta. A adubação de cobertura foi feita segundo recomendações de Sobral (1998), resultando na aplicação, por planta, de 100 g de uréia e de 100 g de cloreto de potássio, 35 dias após o transplante. Realizaramse pulverizações com methamidophos e abamectina para o controle de ácaros e insetos, com aplicações 50 e 270 dias após o transplante. $\mathrm{O}$ controle das plantas daninhas foi feito diversas vezes ao longo do período experimental, por meio do arranquio manual.

No período imediatamente após o transplante das mudas, as irrigações (usando-se água de torneira) foram feitas sem quantificar o volume aplicado mas se buscando o estabelecimento de uma condição ótima de umidade. Decorrido o período de sete semanas, mediante um conjunto balançatalha sustentado por uma estrutura metálica móvel, realizou-se a pesagem dos vasos; desta forma, pôde-se determinar, para cada solo e nível de compactação, o valor médio da umidade do solo, que foi assumida como correspondente ao nível 2. Esta umidade foi utilizada como referência para a implementação das demais condições hídricas, sendo o nível 1 obtido pela elevação da umidade do solo em $0,04 \mathrm{~m}^{3} \mathrm{~m}^{-3}$ e os níveis 3 e 4 obtidos pela redução de 0,04 e $0,08 \mathrm{~m}^{3} \mathrm{~m}^{-3}$ da umidade, respectivamente. Ao ser alterado o solo ou o nível de compactação a umidade de referência também sofreu alteração, como observado na Tabela 4.

O controle da quantidade de água aplicada nos diferentes tratamentos foi realizado entre 90 e 284 dias após o transplante das mudas. A quantificação da água aplicada em cada vaso foi feita com a utilização de um becker, efetuando-se três irrigações semanais. Neste período e a cada intervalo de 10 a 15 dias, foi realizada a pesagem dos vasos. O consumo médio diário de água por vaso, em determinado período, foi calculado somando- se a diferença entre o peso inicial e o final com os volumes aplicados e dividindo-se pelo número de dias. O volume de irrigação em cada vaso no período imediatamente seguinte foi aplicado de acordo com esse consumo médio diário.

Em janeiro de 2008 foram coletados 4 a 5 folíolos da parte central da folha número 2, conforme recomendação de Sobral (1998), para planta de coqueiros jovens. Após a coleta o material foi devidamente identificado e encaminhado ao Laboratório de Solos da UENF. Cada folíolo teve a nervura principal removida; eles foram lavados com algodão embebido em água deionizada, acondicionados em sacos de papel e levados para secar em estufa com circulação forçada de ar e temperatura de $70^{\circ} \mathrm{C}$, até atingir o peso constante. Após seco, o material foi passado em moinho tipo Willey, provido de facas e peneiras de aço inoxidável. O material triturado foi acondicionado em recipientes plásticos até o momento da análise. O procedimento analítico e a metodologia seguida para digestão do tecido vegetal com solução ácida, tal como a determinação dos teores dos nutrientes $\mathrm{P}, \mathrm{K}, \mathrm{Ca}, \mathrm{Mg}, \mathrm{S}, \mathrm{Cl}, \mathrm{Cu}, \mathrm{Fe}, \mathrm{Mn}$ e Zn, foram os descritos por Malavolta et al. (1997), e a determinação do N, pelo método de Nessler, segundo Jackson (1965).

\section{RESULTADOS E DISCUSSÃO}

Exceção feita ao P, S, Fe e Zn, para os demais nutrientes observou-se efeito significativo $(\mathrm{p}<0,01)$ das classes de solo (Tabela 5). Verificou-se também efeito significativo para o nitrogênio na interação solo x umidade e para o manganês e o cloro, na interação solo x compactação.

De modo geral observou-se que as plantas apresentavam, no momento da coleta, bom estado nutricional em ambos os solos (Tabela 6). Resultados similares para o N, Mg e Ca, inferiores para o $\mathrm{P}$ e o $\mathrm{K}$, e superior para o $\mathrm{S}$ foram encontrados por Santos (2002) para a folha número 2 do coqueiro anãoverde com 3 anos. Os teores de $\mathrm{P}$ e $\mathrm{K}$ obtidos neste trabalho possivelmente sejam resultantes do expressivo teor inicial de fósforo no CXbd e da adubação com Super Fosfato Triplo (feita no PAdx) no momento do enchimento dos vasos, bem

Tabela 4. U midade, porosidade de aeração e potencial mátrico após implementação das quatro condições hídricas ao Argissolo (PAdx) e ao Cambissolo (CXbd), nos quatro níveis de compactação (Cp1; Cp2; Cp3; e Cp4)

\begin{tabular}{|c|c|c|c|c|c|c|c|c|}
\hline & \multicolumn{2}{|c|}{ Irrigação 1} & \multicolumn{2}{|c|}{ Irrigação 2} & \multicolumn{2}{|c|}{ Irrigação 3} & \multicolumn{2}{|c|}{ Irrigação 4} \\
\hline & PAdx & CXbd & PAdx & CXbd & PAdx & CXbd & PAdx & CXbd \\
\hline & \multicolumn{8}{|c|}{ Umidade do solo $\left(\mathrm{m}^{3} \mathrm{~m}^{-3}\right)$} \\
\hline Cp1 & 0,34 & 0,41 & 0,30 & 0,37 & 0,26 & 0,33 & 0,22 & 0,29 \\
\hline Cp2 & 0,36 & 0,42 & 0,32 & 0,38 & 0,28 & 0,34 & 0,24 & 0,30 \\
\hline Cp3 & 0,37 & 0,43 & 0,33 & 0,39 & 0,29 & 0,35 & 0,25 & 0,31 \\
\hline \multirow[t]{2}{*}{ Cp4 } & 0,39 & 0,44 & 0,35 & 0,40 & 0,31 & 0,36 & 0,27 & 0,32 \\
\hline & \multicolumn{8}{|c|}{ Porosidade de aeração $\left(\mathrm{m}^{3} \mathrm{~m}^{-3}\right)$} \\
\hline Cp1 & 0,28 & 0,18 & 0,32 & 0,24 & 0,36 & 0,26 & 0,40 & 0,30 \\
\hline $\mathrm{Cp} 2$ & 0,19 & 0,14 & 0,23 & 0,18 & 0,27 & 0,22 & 0,31 & 0,26 \\
\hline $\mathrm{Cp3}$ & 0,14 & 0,07 & 0,18 & 0,11 & 0,22 & 0,15 & 0,26 & 0,19 \\
\hline \multirow[t]{2}{*}{ Cp4 } & 0,04 & 0,03 & 0,08 & 0,07 & 0,12 & 0,11 & 0,16 & 0,15 \\
\hline & \multicolumn{8}{|c|}{ Potencial mátrico $(\mathrm{kPa})$} \\
\hline Cp1 & $-2,39$ & $-0,26$ & $-3,54$ & $-0,61$ & $-5,55$ & $-0,95$ & $-9,85$ & $-2,34$ \\
\hline $\mathrm{Cp} 2$ & $-2,59$ & $-1,14$ & $-4,26$ & $-1,65$ & $-8,13$ & $-2,64$ & $-21,37$ & $-5,00$ \\
\hline $\mathrm{Cp3}$ & $-2,53$ & $-1,00$ & $-4,40$ & $-1,88$ & $-8,70$ & $-4,13$ & $-23,14$ & $-11,88$ \\
\hline Cp4 & $-2,40$ & $-1,30$ & $-6,92$ & $-2,18$ & $-23,63$ & $-4,27$ & $-199,28$ & $-11,06$ \\
\hline
\end{tabular}


Tabela 5. Valores de $\mathrm{F}$ e significância das diferentes fontes de variação e coeficiente de variação (CV), para os teores de nitrogênio $(\mathrm{N})$, fósforo $(\mathrm{P})$, magnésio $(\mathrm{Mg})$, potássio $(\mathrm{K})$, cál cio $(\mathrm{Ca})$, enxofre $(\mathrm{S})$, manganês $(\mathrm{Mn})$, ferro $(\mathrm{Fe})$, cobre $(\mathrm{Cu})$, zinco (Zn) e cloro (Cl)

\begin{tabular}{|c|c|c|c|c|c|c|c|c|c|c|c|}
\hline Fonte de variação & $\mathbf{N}$ & $\mathbf{P}$ & $\mathrm{Mg}$ & $\mathrm{K}$ & $\mathrm{Ca}$ & $\mathbf{S}$ & $M n$ & $\mathrm{Fe}$ & $\mathrm{Cu}$ & Zn & $\mathrm{Cl}$ \\
\hline Bloco & $0,03^{\mathrm{ns}}$ & $0,55^{\mathrm{ns}}$ & $3,03^{\mathrm{ns}}$ & $1,94^{\mathrm{ns}}$ & $2,24^{\mathrm{ns}}$ & $0,52^{\mathrm{ns}}$ & $1,69^{\mathrm{ns}}$ & $1,59^{\mathrm{ns}}$ & $0,31^{\mathrm{ns}}$ & $6,98 * *$ & $2,98^{\mathrm{ns}}$ \\
\hline Solo & $10,40 * *$ & $1,87^{\mathrm{ns}}$ & $14,00 * *$ & $4,68 * *$ & $81,05 * *$ & $0,15^{\mathrm{ns}}$ & $18,99 * *$ & $0,38^{\mathrm{ns}}$ & $53,19 * *$ & $8^{\text {ns }}$ & $14,11 * *$ \\
\hline Comp. & $0,52^{\mathrm{ns}}$ & $2,46^{\mathrm{ns}}$ & $0,09^{\text {ns }}$ & $1,70^{\mathrm{ns}}$ & $0,35^{\mathrm{ns}}$ & $1,47^{\mathrm{ns}}$ & $4,18 *$ & $1,04^{\mathrm{ns}}$ & $1,20^{\mathrm{ns}}$ & $1,45^{\mathrm{ns}}$ & $2,50^{\mathrm{ns}}$ \\
\hline Solo x Comp. & $0,55^{\text {ns }}$ & $1,24^{\text {ns }}$ & $0,11^{\mathrm{ns}}$ & $1,56^{\mathrm{ns}}$ & $1,09^{\mathrm{ns}}$ & $2,01^{\text {ns }}$ & $2,78 *$ & $0,06^{\text {ns }}$ & $1,98^{\text {ns }}$ & $0,33^{\text {ns }}$ & $2,87 *$ \\
\hline Umidade & $0,21^{\text {ns }}$ & $0,33^{\text {ns }}$ & $2,54^{\mathrm{ns}}$ & $0,75^{\mathrm{ns}}$ & $2,03^{\text {ns }}$ & $0,57^{\mathrm{ns}}$ & $0,42^{\text {ns }}$ & $1,90^{\mathrm{ns}}$ & $0,55^{\text {ns }}$ & $0,65^{\text {ns }}$ & $2,63^{\text {ns }}$ \\
\hline Solo x Umid. & $2,88 *$ & $0,14^{\mathrm{ns}}$ & $0,09^{\text {ns }}$ & $0,29^{\text {ns }}$ & $2,02^{\text {ns }}$ & $0,42^{\text {ns }}$ & $0,46^{\text {ns }}$ & $0,71^{\mathrm{ns}}$ & 0,29 ns & $0,70^{\text {ns }}$ & $0,92^{\text {ns }}$ \\
\hline Comp. x Umid. & $0,94^{\text {ns }}$ & $0,42^{\text {ns }}$ & $0,53^{\text {ns }}$ & $0,62^{\text {ns }}$ & $0,93^{\text {ns }}$ & $1,64^{\text {ns }}$ & $0,87^{\text {ns }}$ & $0,17^{\text {ns }}$ & $1,02^{\text {ns }}$ & $0,43^{\text {ns }}$ & $1,92^{\text {ns }}$ \\
\hline Solo $x$ Comp. $x$ Umid. & $1,75^{\text {ns }}$ & $1,52^{\mathrm{ns}}$ & $0,68^{\text {ns }}$ & $0,43^{\mathrm{ns}}$ & $0,95^{\mathrm{ns}}$ & $1,32^{\text {ns }}$ & $0,48 \mathrm{~ns}$ & $1,56^{\text {ns }}$ & 0,87 ns & $0,55^{\mathrm{ns}}$ & $1,20^{\text {ns }}$ \\
\hline $\mathrm{CV} \%$ & 9,47 & 8,27 & 13,47 & 22,55 & 17,53 & 17,21 & 28,00 & 35,83 & 16,66 & 19,01 & 18,93 \\
\hline
\end{tabular}

Obs: $*:<0,05 ; * *:<0,01 ;$ ns: não significativo; Comp.= compactação e Umid.= umidade

Tabela 6. Teores de $\mathrm{P}, \mathrm{K}, \mathrm{Ca}, \mathrm{Mg}, \mathrm{S}, \mathrm{Cu}$, Fe e $\mathrm{Zn}$ determinados na folha número 2 de plantas de coqueiro para 0 Argissolo Amarelo Distrocoeso latossólico (PAdx) e do Cambissolo Háplico Tb Distrófico típico gleico (CXbd)

\begin{tabular}{|c|c|c|c|c|c|c|c|c|c|c|c|}
\hline \multirow{2}{*}{ Solo } & $\mathbf{N}$ & $\mathbf{P}$ & $\mathrm{Mg}$ & K & $\mathrm{Ca}$ & 5 & $\overline{\mathrm{Cl}}$ & $M n$ & $\mathrm{Fe}$ & $\mathrm{Cu}$ & $\mathrm{Zn}$ \\
\hline & & & & $\mathrm{g} \mathrm{kg}^{-1}$ & & & & \multicolumn{4}{|c|}{$\mathrm{mg} \mathrm{kg}^{-1}$} \\
\hline PAdx & 21,0 & $2,04 a^{1}$ & $3,15 b$ & $18,8 \mathrm{a}$ & $7,15 \mathrm{a}$ & $1,37 \mathrm{a}$ & 9,44 & 156 & $151 \mathrm{a}$ & $3,20 \mathrm{~b}$ & $13,9 \mathrm{a}$ \\
\hline CXbd & 22,5 & $2,10 a$ & $3,50 a$ & $17,2 \mathrm{~b}$ & $5,01 \mathrm{~b}$ & $1,38 \mathrm{a}$ & 8,06 & 118 & $141 \mathrm{a}$ & $4,18 \mathrm{a}$ & $14,9 a$ \\
\hline
\end{tabular}

${ }^{1}$ Médias seguidas da mesma letra (na coluna) não diferem estatisticamente pelo teste $\mathrm{F}$

como da aplicação de $\mathrm{KCl}$ em cobertura em ambos os solos, após 35 dias do transplante das mudas.

O cálcio e o enxofre, por serem nutrientes de baixa mobilidade na planta, podem ser comparados com os teores determinados nas folhas mais velhas ( 9 ou 14), usualmente utilizadas na análise foliar de coqueiros em produção. Comparando os teores considerados adequados por Alves (2003) observou-se, para ambos os solos, que os valores estão dentro ou acima desta faixa (Tabela 6), indicando que as plantas estavam bem nutridas com esses nutrientes. Para o N, P, K e Mg, embora esta comparação seja menos adequada, pois são nutrientes que sofrem translocação na planta, os teores determinados por Alves (2003) na folha 14 são inferiores aos apresentados na Tabela 6. Para esses nutrientes, valores similares foram constatados por Teixeira \& Silva (2003) para a folha número 4 de plantas de coqueiro anão-verde com 28 meses de idade, nas quais possivelmente ainda não houve grande translocação desses para as folhas mais jovens.

Comparando-se as classes de solo observa-se, na Tabela 6, que as plantas não se diferenciaram quanto aos teores foliares de $\mathrm{P}$, porém as cultivadas no Cambissolo apresentaram teores de $\mathrm{Mg}$ superiores aos das cultivadas no Argissolo. A superioridade do Cambissolo em disponibilizar mais Mg para as plantas certamente está associada ao teor inicial deste elemento no solo (Tabela 1). Para o $\mathrm{Se}$ a despeito deste nutriente ter sua disponibilidade diretamente ligada ao teor de carbono do solo (Marschner, 1990) e do CXbd possuir duas vezes mais carbono que PAdx, não se observou diferença entre os solos quanto ao suprimento de enxofre para as plantas, o que se justifica pela aplicação de Super Fosfato Triplo no PAdx durante a montagem do experimento.

Para o potássio e o cálcio as plantas cultivadas no Argissolo apresentam teores mais elevados em suas folhas. Para o cálcio (apesar de ser realizada calagem nos dois solos objetivando elevar a saturação por bases a 70\%), esta diferença certamente está relacionada com a quantidade disponível deste elemento após o período experimental, sendo determinados, para o Argissolo e Cambissolo, respectivamente, 39,1 e 18,2 mmol $\mathrm{kg}^{-1}$. Já para o K, a despeito de ambos os solos apresentarem teor muito alto na profundidade de $0,0-0,20 \mathrm{~m}$ após o período experimental, a menor absorção das plantas cultivadas no Cambissolo pode estar relacionada com o percentual de argila e ao tipo deste colóide presente neste solo. Como é um solo menos intemperizado, sua expansibilidade indica presença de certa quantidade de argila tipo 2:1, dentre as quais algumas de elevado poder de fixação de K. Para solos que possuem maior percentual de areia ou solos mais intemperizados (como o Argissolo), nos quais predomina a caulinita como mineral secundário, geralmente se verifica maior disponibilidade de potássio para as plantas (Brunetto et al., 2005). Também pode ter contribuído para as plantas cultivadas no Cambissolo apresentarem menores teores de $\mathrm{Ca}$ e $\mathrm{K}$ em suas folhas, o fato deste solo ter proporcionado maior crescimento do coqueiro, conforme relatado por Peçanha (2007) resultando, assim, em uma diluição do teor desses elementos nas folhas.

Quanto ao N verificou-se, no CXbd, que os teores nas folhas do coqueiro não foram influenciados significativamente pela umidade do solo, obtendo-se teor médio geral de $22,5 \mathrm{~g} \mathrm{~kg}^{-1}$ (Tabela 6; Figura 2), enquanto para o PAdx se verificou um incremento linear nesse teor, com o aumento da umidade do solo (Figura 2). Tal comportamento fez com que, para o solo mais seco, os teores foliares de $\mathrm{N}$ no PAdx fossem significativamente inferiores aos verificados para o CXbd. Esta menor disponibilidade de nitrogênio nas baixas umidades pode estar relacionada ao fato de que, para o Argissolo, a redução da umidade leva a uma redução expressiva da condutividade hidráulica (Bernardes, 2005) e da absorção de água pelas plantas (Peçanha, 2007), com consequente redução do fluxo de massa de $\mathrm{N}$ até as raízes. No Cambissolo, pelo contrário, a redução da condutividade hidráulica com a diminuição da umidade é menos expressiva (Bernardes, 2005), fazendo com que se mantenha um nível mais elevado de absorção de água pelas plantas 


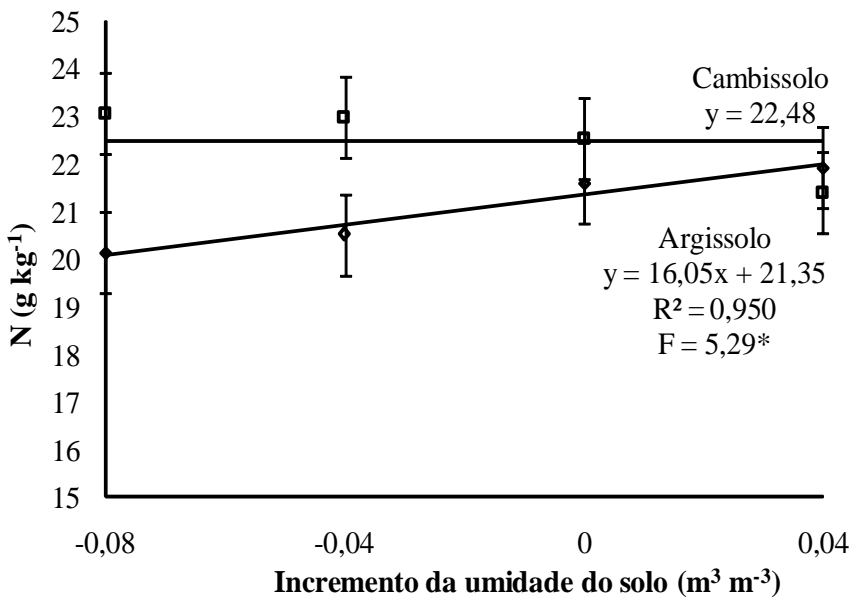

Obs.: Barras verticais representam o desvio mínimo significativo pelo teste de Tukey a $5 \%$ de probabilidade, indicando haver diferença entre os solos quando não se interceptam

Figura 2. Teor de nitrogênio na fol ha número 2 de plantas de coqueiro em função do incremento da umidade do solo, para o Cambissolo e o Argissolo

(Peçanha, 2007), o que proporciona maior mobilidade de $\mathrm{N}$ no solo e sua maior absorção por fluxo de massa. Neste mesmo experimento Peçanha (2007), verificou que o comportamento da clorofila foi idêntico ao do N, corroborando com os dados de Argenta et al. (2001), ao demonstrarem que este pigmento tem elevada correlação positiva com o suprimento de $\mathrm{N}$.

Diferenças na disponibilidade de $\mathrm{N}$ frequentemente são relacionadas ao teor de matéria orgânica no solo. Segundo Souza \& Melo (2000), solos mais ricos em carbono possuem maior quantidade disponível de nitrogênio para as plantas, o que justifica, no presente caso, os maiores teores foliares de N, no Cambissolo. Além disso, para o mesmo nível de compactação solos que apresentam teor mais elevado de matéria orgânica possuem maior capacidade de reter água (Silva et al., 2002). Rocha et al. (2008) argumentam que, com a redução do teor de água para níveis abaixo da capacidade de campo, a mineralização do nitrogênio diminui. Por outro lado, em teores de água acima da capacidade de campo também ocorre redução em razão da baixa concentração de oxigênio necessário às reações de mineralização. Medeiros et al. (2005) observaram, em um Neossolo Flúvico, redução no teor de N com o aumento da umidade.

Para todos os micronutrientes estudados observa-se que em ambos os solos os teores foliares são considerados adequados para a cultura do coqueiro (Tabela 6), estando acima dos níveis críticos apresentados por Sobral (1998), para a folha número 4 de plantas jovens. Referidos teores também estão de acordo com os encontrados por Santos (2002), para a folha número 2 de plantas de coqueiro com 3 anos de idade, e com os teores determinados por Teixeira \& Silva (2003), para a folha número 4 de diferentes variedades e híbridos de coqueiro com 2 anos e 4 meses de idade. Já Alves (2003) determinou, para a folha número 9 de plantas de coqueiro com elevada produtividade, valores similares para o cobre, ferro, manganês e cloro, e inferiores para o zinco. Esta diferença para o Zn se deve, provavelmente, à maior mobilidade deste elemento na planta.
Observa-se, na Tabela 6, que não houve diferenças entre as classes de solo quanto aos teores foliares de ferro e zinco, apesar das plantas cultivadas no Cambissolo terem apresentado teor de cobre superior ao determinado nas plantas cultivadas no Argissolo. Esta diferença pode estar relacionada ao maior teor de matéria orgânica presente no Cambissolo. Conforme Zanão Júnior et al. (2007), o teor de cobre apresenta correlação positiva e altamente significativa com os teores de matéria orgânica presente no solo.

Quanto ao $\mathrm{Mn}$ e ao $\mathrm{Cl}$ verificou-se, no $\mathrm{CXbd}$, que seus teores nas folhas do coqueiro não foram influenciados significativamente pela densidade do solo, obtendo-se teor médio geral de $118,6 \mathrm{mg} \mathrm{kg}^{-1}$ para o $\mathrm{Mn}$ e de $8,06 \mathrm{~g} \mathrm{~kg}^{-1}$ para o $\mathrm{Cl}$ (Tabela 6; Figuras 3A e 3B, respectivamente). No PAdx, no entanto, constatou-se a ocorrência do efeito quadrático da densidade do solo sobre os teores foliares de Mn (Figura 3A) e de efeito linear decrescente sobre os teores foliares de $\mathrm{Cl}$ (Figura 3B).

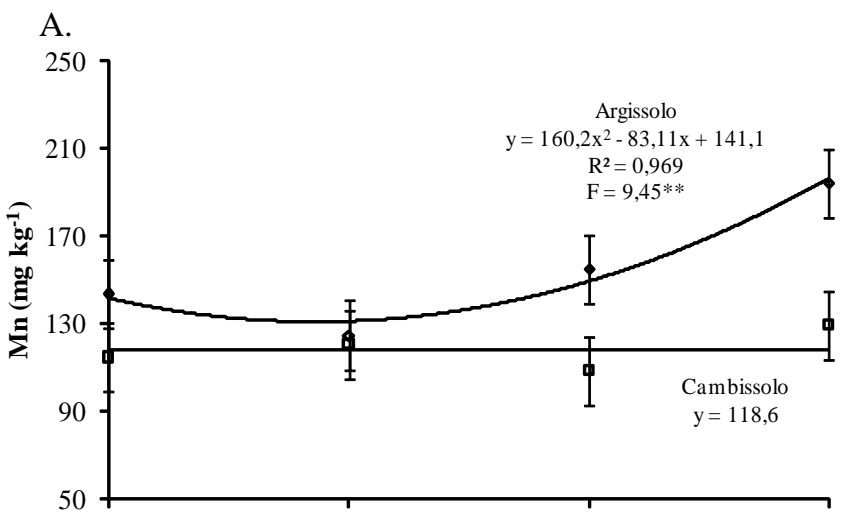

B.

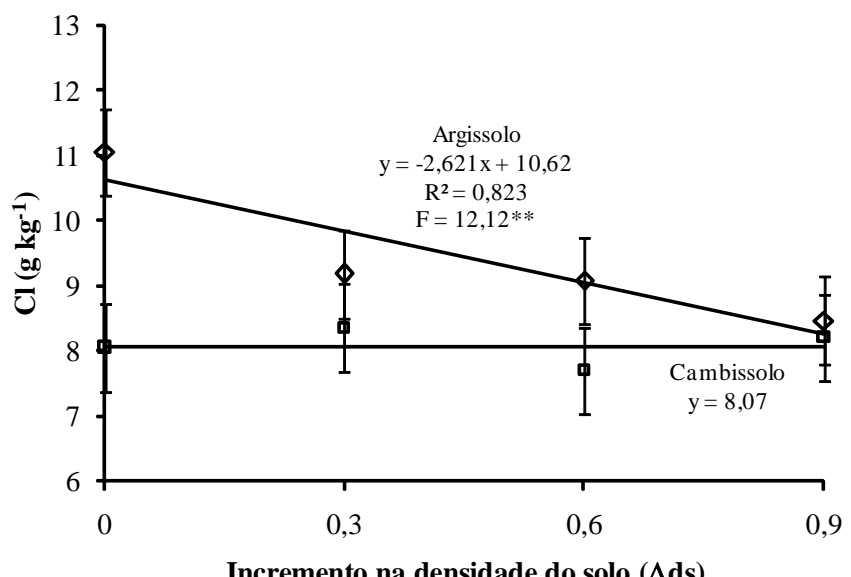

Obs.: Barras verticais representam o desvio mínimo significativo pelo teste de Tukey a $5 \%$ de probabilidade indicando que há diferença entre solos, quando não se interceptam

Figura 3. Teor de manganês - $\mathrm{Mn}(\mathrm{A})$ e cloro - $\mathrm{Cl}$ (B) na folha número 2 de plantas de coqueiro em função da umidade no Argissolo e no Cambissolo

A resposta quadrática do $\mathrm{Mn}$ nas plantas cultivadas no Argissolo (Figura 3A) fez com que, para o solo mais compactado (compactação adicional de 0,6 e 0,9 da $\Delta$ ds), os teores foliares no PAdx fossem significativamente superiores aos verificados para o CXbd. No Argissolo, devido ao menor teor de carbono, os níveis mais elevados de compactação resultaram, possivelmente, 
em uma atividade biológica menor, o que pode ter contribuído para um suprimento maior de manganês para o coqueiro. Conforme Miyazawa et al. (1993), o aumento da atividade biológica do solo favorece a formação de Mn-complexo orgânico, diminuindo, assim, a disponibilidade deste elemento para as plantas. Para as plantas cultivadas no Cambissolo, por outro lado, os menores teores foliares de manganês se devem, provavelmente, ao teor mais elevado de matéria orgânica no solo, cuja consequência é uma atividade biológica maior.

Segundo Pavan \& Miyazawa (1984), alterações bruscas da temperatura e da umidade do solo favorecem a disponibilidade de manganês. Conforme os autores, solos expostos à luz solar ou a elevadas temperaturas ou que sofrem maior alternância de umedecimento e secagem (fatores que reduzem a atividade biológica), apresentam teores mais elevados de manganês. No Cambissolo, além do maior teor de matéria orgânica, é relevante considerar o fato do valor absoluto da umidade ser, em cada nível de irrigação utilizado, $0,06 \mathrm{~m}^{3} \mathrm{~m}^{-3}$ superior ao do Argissolo (Tabela 4). Esta maior umidade faz com que o Cambissolo tenha capacidade térmica maior que a do Argissolo, tornando-o menos sujeito a oscilações de temperatura. A partir dos dados da Tabela 4 e se admitindo calor específico de $1,0 \mathrm{cal} \mathrm{cm}^{-3}{ }^{\circ} \mathrm{C}^{-1}$ para a água e $0,4 \mathrm{cal} \mathrm{cm}^{-3}{ }^{\circ} \mathrm{C}^{-1}$ para a matriz de ambos os solos (Reichardt \& Timm, 2004), pode-se obter, para o menor nível de compactação, o valor de capacidade térmica de $0,432 \mathrm{cal} \mathrm{cm}^{3}{ }^{\circ} \mathrm{C}^{1}$ para o Argissoloe de 0,514 cal cm ${ }^{-3} \mathrm{C}^{-1}$ para o Cambissolo (superioridade de 19,0\%). Para o maior nível de compactação os valores são de $0,558 \mathrm{cal} \mathrm{cm}^{-3}{ }^{\circ} \mathrm{C}^{-1}$ para o Argissolo e de $0,592 \mathrm{cal} \mathrm{cm}^{-3}{ }^{\circ} \mathrm{C}^{-1}$ para o Cambissolo (superioridade de 6,1\%). Em experimentos conduzidos em vasos a superfície de troca de calor com a atmosfera é maior e a oscilação da temperatura é mais expressiva que a verificada em condições de campo. Assim, no presente caso a maior absorção de Mn pelas plantas cultivadas no Argissolo nesses níveis de compactação pode, de fato, estar associada a uma oscilação maior da temperatura do solo.

Outro aspecto a considerar é que a maior compactação do solo também pode aumentar a disponibilidade de $\mathrm{Mn}$ por diminuir a oxigenação e favorecer a redução de $\mathrm{MnO}_{2}$ para $\mathrm{MnO}$, que é a forma absorvida pelas plantas (Marschner, 1990). A ausência do efeito da compactação no teor de manganês nas plantas cultivadas no Cambissolo se deve, provavelmente, aos atributos químicos e físicos deste solo que, por possuir teor de matéria orgânica mais elevada e agregados mais estáveis tornase menos sensível às oscilações de temperatura e umidade e aos níveis de compactação utilizados.

A resposta linear decrescente verificada para o cloro nas plantas cultivadas no Argissolo (Figura 3B) ocorreu em razão da maior absorção deste nutriente nos menores níveis de compactação, o que fez com que, para o solo menos compactado, seu teor foliar fosse significativamente superior ao obtido nas plantas cultivadas no Cambissolo. O maior desenvolvimento radicular das plantas no menor nível de compactação permite uma exploração melhor do solo e, assim, maior absorção de água e nutrientes pelas plantas. Como a mobilidade do cloro no solo se dá, predominantemente, por fluxo de massa (Marschner, 1990), nos níveis elevados de compactação ocorre a restrição do desenvolvimento radicular das plantas no Argissolo, o que leva a uma absorção menor de água e de cloro. Para o Cambissolo o efeito da compactação sobre o teor de cloro nas plantas não existiu, o que se justifica por este solo apresentar maior teor de matéria orgânica e manter, quando compactado, atributos físicos mais favoráveis ao desenvolvimento radicular que o Argissolo. Por exemplo, com ambos os solos na capacidade de campo, a resistência à penetração aumenta de 0,39 para 1,82 MPa no Cambissolo e de 0,14 para 4,11 MPa no Argissolo, sendo este último valor considerado restritivo ao crescimento radicular.

\section{CONCLUSÕES}

1. Os solos atuaram de forma diferenciada no suprimento de nutrientes para as plantas, com teor mais elevado de $\mathrm{Mg}$ e $\mathrm{Cu}$ naquelas cultivadas no Cambissolo e de $\mathrm{K} \mathrm{e} \mathrm{Ca}$, nas cultivadas no Argissolo.

2. No Argissolo, a redução da umidade do solo alterou a disponibilidade de nitrogênio, fazendo com que as plantas cultivadas nos menores níveis de umidade apresentassem teores mais baixos deste elemento.

3. A compactação do solo aumentou o teor foliar de manganês e reduziu o de cloro nas plantas cultivadas no Argissolo.

\section{AgRAdECIMENTOS}

Os autores agradecem ao Horto Municipal de QuissamãRJ, pela cessão das mudas de coqueiro, e à FAPERJ, pelo auxílio financeiro ao projeto (Proc. $n^{\circ}$ E-26/171.618/2001).

\section{LITERATURA CITADA}

Ahmad, N.; F.U. Hassan, F. U.; R. K. Belford, R. K. Effect of soil compaction in the sub-humid cropping environment in Pakistan on uptake of NPK and grain yield in wheat (Triticum aestivum) I. Compaction. Field Crops Research, v.110, p.5460, 2009.

Alakukku, L.; Weisskopf, P.; Chamen, W. C. T.; Tijink, F. G. J.; Van Der Linden, J. P.; Pires, S.; Sommer, C.; Spoor, G. Prevention strategies for field traffic-induced subsoil compaction: a review. Part I - Machine/soil interactions, Soil and Tillage Research, v.73, p.45-160, 2003.

Alves, E. A. B. Estabelecimento de faixas de teores adequados de nutrientes foliares em maracujazeiro amarelo, mamoeiro formosa e coqueiro anão-verde cultivados no Norte Fluminense. Campos dos Goytacazes: UENF, 2003. 64p. Tese Doutorado

Argenta, G.; Silva, P. R. F.; Bortolini, C. G. Clorofila na folha como indicador do nível de nitrogênio em cereais. Ciência Rural, v.31, p.715-722, 2001.

Barzegar, A. R.; Nadian, H.; Heidari, F.; Herbert, S. J.; Hashemi, A. M. Interaction of soil compaction, phosphorus and zinc on clover growth and accumulation of phosphorus. Soil and Tillage Research, v.87, p.155-162, 2006.

Bernardes, R. S. Condutividade hidráulica de três solos da Região Norte Fluminense. Campos dos Goytacazes: UENF, 2005. 80p. Dissertação Mestrado 
Beulter, A. N.; Centurion, J. F. Compactação do solo no desenvolvimento radicular e na produtividade da soja. Pesquisa Agropecuária Brasileira, v.39, p.581-588, 2004.

Brunetto, G.; Gatiboni, L. C.; Rheinheimer, D. S.; Saggin, A.; Kaminski, J. Nível crítico e resposta das culturas ao potássio em um Argissolo sob sistema plantio direto. Revista Brasileira de Ciência do Solo, v.29, p.569-571, 2005.

Cardoso, E. G.; Zotarelli, L.; Piccinin, J. L.; Torres, E.; Saraiva, O. F.; Guimarães, M. F. Sistema radicular da soja em função da compactação do solo no sistema de plantio direto. Pesquisa Agropecuária Brasileira, v.41, p.493-501, 2006.

Cintra, F. L. D.; Portela, J. C.; Nogueira, L. C. Caracterização física e hídrica em solos dos Tabuleiros Costeiros no Distrito de Irrigação Platô de Neópolis. Revista Brasileira de Engenharia Agrícola e Ambiental, v.8, p.45-50, 2004.

Corrêa, J. B. D.; Andrade, L. A.; Dias Júnior, M. S.; Alves, V. G. Efeito da compactação na concentração foliar de nutrientes na cana-de-açúcar em três tipos de solos. In: FERTBIO, 1998, Lavras. Anais..... Lavras: UFLA/SBCS/SBM, 1998, p.91-94.

Costa, J. P. V. da; Barros, N. F.; Bastos, A. L.; Albuquerque, A. W. Fluxo difusivo de potássio em solos sob diferentes níveis de umidade e de compactação. Revista Brasileira de Engenharia Agrícola e Ambiental, v.13, p.56-62, 2009.

EMBRAPA - Empresa Brasileira de Pesquisa Agropecuária. Manual e métodos de análises de solo. 2.ed., Rio de Janeiro: Embrapa Solos, 1997. 212p.

EMBRAPA - Empresa Brasileira de Pesquisa Agropecuária. Sistema Brasileiro de Classificação dos Solos. Rio de Janeiro: Embrapa Solos, 2006. 306p.

Foloni, J. S. S.; Calonego, J. C.; Lima, S. L. Efeito da compactação do solo no desenvolvimento aéreo e radicular de cultivares de milho. Pesquisa Agropecuária Brasileira, v.38, p.947-953, 2003.

Hakansson, I.; Stenberg, M.; Rydberg, T. Long term experiments with different depths of mouldboard plough in Sweden. Soil and Tillage Research, v.46, p.209-223, 1998.

Hamza, M. A.; Anderson, W. K. Soil compaction in cropping systems A review of the nature, causes and possible solutions. Soil \& Tillage Research, v.82, p.121-145, 2005.

Jackson, M. L. Soil chemical analysis. New Jersey: PrenticeHall. 1965. 498p.

Lipiec, J.; Hatano, R. Quantification of compaction effects on soil physical properties and crop growth. Geoderma, v.116, p.107-136, 2003.

Malavolta, E.; Vitti, G. C.; Oliveira, S. A. Avaliação do estado nutricional das plantas; princípios e aplicações. 2.ed. Piracicaba: Potafos, 1997. 319p.

Marinho, J. L. M.; Gheyi, H. R.; Fernandes, P. D. Cultivo do coco "Anão Verde" irrigado com águas salinas. Pesquisa Agropecuária Brasileira, v.41, p.1277-1284, 2006.

Marschner, H. Mineral nutrition of higher plants. London: Academic Press, 1990. 674p.

Medeiros, R. D.; Soares, A. A.; Guimarães, R. M. Compactação do solo e manejo da água I: efeito sobre a absorção de N, P, $\mathrm{K}$, massa seca de raízes, e parte aérea de plantas de arroz. Ciência Agrotecnologia, v.29, p.940-947, 2005.
Miyazawa, M.; Pavan, M. A.; Martin Neto, L. Provável mecanismo de liberação e manganês no solo. Pesquisa Agropecuária Brasileira, v.28, p.725-731, 1993.

Oliveira, V. S.; Rolim, M. M.; Vasconcelos, R. F. B.; Costa, Y. D. J.; Pedrosa, E. M. R. Compactação de um Argissolo Amarelo distrocoeso submetido a diferentes manejos. Revista Brasileira de Engenharia Agrícola e Ambiental, v.14, p.914-920, 2010.

Pavan, M. A.; Miyazawa, M. Disponibilidade de manganês no solo: dificuldades e problemas na interpretação da analise para fins de fertilidade. Revista Brasileira de Ciência do Solo, v.8, p.285-289, 1984.

Peçanha, A. L. Relações hídricas e trocas gasosas do coqueiro anão-verde em função da compactação, lâmina de irrigação e classe de solo. Campos dos Goytacazes: UENF, 2007. 73p. Dissertação Mestrado

Queiroz-Voltan, R. B.; Nogueira, S. S. S.; Miranda, M. A. C. Aspectos da estrutura da raiz e do desenvolvimento de plantas de soja em solos compactados. Pesquisa Agropecuária Brasileira, v.35, p.929-938, 2000.

Ralisch; R.; Miranda, T. M.; Okumura, R. S.; Barbosa, G. M. C.; Guimarães, M. F.; Scopel, E.; Balbino, E. C. Resistência à penetração de um Latossolo Vermelho Amarelo do Cerrado sob diferentes sistemas de manejo. Revista Brasileira de Engenharia Agrícola e Ambiental, v.12, p.381-384, 2008.

Reichardt, K.; Timm, L. C. Solo, planta e atmosfera. Conceitos, processos e aplicações. Barueri: Manole, 2004. 478p.

Rocha, F. A.; Martinez, M. A.; Matos, A. T.; Cantarutti, R. B.; Silva, J. O. Modelo numérico do transporte de nitrogênio no solo. Parte II: Reações biológicas durante a lixiviação. Revista Brasileira de Engenharia Agrícola e Ambiental, v.12, p.54-61, 2008.

Rodrigues, P. N. F.; Rolim, M. M.; Bezerra Neto, E.;. Pedrosa, E. M. R.; S. Oliveira, V. S. Crescimento e composição mineral do milho em função da compactação do solo e da aplicação de composto orgânico. Revista Brasileira de Engenharia Agrícola e Ambiental, v.13, p.94-99, 2009.

Santos, A. L. Estabelecimento de normas de amostragem foliar para avaliação do estado nutricional e adubação mineral do coqueiro anão-verde na região Norte Fluminense. Campos dos Goytacazes: UENF, 2002. 83p. Tese Doutorado

Santos, D. R.; Gatiboni, L. C.; Kaminski, J. Fatores que afetam a disponibilidade do fósforo e o manejo da adubação fosfatada em solos sob sistema plantio direto. Ciência Rural, v.38, n.2, p.576-586, 2008.

Santos, G. A. dos; Dias Júnior, M. de S.; Guimarães, P. T. G.; Furtini Neto, A. E. Diferentes graus de compactação e fornecimento de fósforo influenciando no crescimento de plantas de milho (Zea mays L.) cultivadas em solos distintos. Ciência e Agrotecnologia, v.29, p.740-752, 2005.

Silva, S. R.;. Barros, N. F.; Costa, L. M. Atributos físicos de dois Latossolos afetados pela compactação do solo. Revista Brasileira de Engenharia Agrícola e Ambiental, v.10, p.842847, 2006.

Silva, V. R.; Reinert, D. J.; Soares, J. M. Fatores controladores da compressibilidade de um Argissolo Vermelho-Amarelo distrófico arênico e de um Latossolo Vermelho distrófico típico. I - Estado inicial de compactação. Revista Brasileira de Ciência do Solo, v.26, p.1-8, 2002. 
Sobral, L. F. Nutrição e adubação do coqueiro. In: Ferreira, J. M. S., WarWick, D. R. N.; Siqueira, L. A. (ed.) A cultura do coqueiro no Brasil. 2.ed. Brasília: Embrapa CPATC. 1998, cap.3, p.65-72.

Souza, W. J. O.; Melo, W. J. Teores de nitrogênio no solo e nas frações da matéria orgânica sob diferentes sistemas de produção de milho. Revista Brasileira de Ciência do Solo, v.24, p.885-896, 2000.

Stacanti, G.; Nogueira, J. B.; Vilar, O. M. Compactação do solo. São Paulo: Universidade de São Paulo, 1981. 13p. Ensaios de laboratório em mecânica do solo, 7.

Teixeira, L. A. J.; Bataglia, O. C.; Buzetti, S.; Fulani Junior, E. Adubação com NPK em coqueiro anão-verde (Cocous nucifera L.) - Atributos químicos do solo e nutrição da planta. Revista Brasileira de Fruticultura, v.27, p.115-119, $2005 a$.
Teixeira, L. A. J.; Bataglia, O. C.; Buzetti, S.; Fulani Júnior, E.; Isepon, J. S. Adubação com NPK em coqueiro anão-verde (Cocous nucifera L.) - Rendimento e qualidade dos frutos. Revista Brasileira de Fruticultura, v.27, p.120-123, 2005b.

Teixeira, L. A. J.; Silva, J. A. A. Nutrição mineral de populações e híbridos de coqueiro (Cocos nucifera L.) cultivados em Bebedouro (SP). Revista Brasileira de Fruticultura, v.25, p.371-374, 2003.

Villani, E. M. A.; Novais, R. F.; Barros, N. F.; Fontes, L. E. F.; Neves, J. C. L. Difusão de fósforo em solos com diferentes texturas e níveis de umidade. Revista Brasileira de Ciência do Solo, v.17, p.343-347, 1993.

Zanão Júnior, L. A.; Lana, R. M. Q.; Guimarães, E. C. Variabilidade espacial do $\mathrm{pH}$, teores de matéria orgânica e micronutrientes em profundidades de amostragem num Latossolo Vermelho sob semeadura direta. Ciência Rural, v.37 p.1000-1007, 2007. 